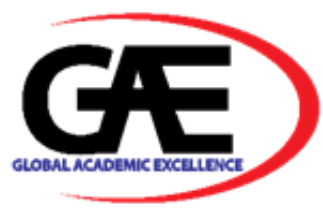

\title{
DESIGN OF MOBILE HEART DISEASE APPLICATION BASED ON USERS PERSPECTIVE USING DESIGN SCIENCE RESEARCH APPROACH
}

\author{
Muhammad Sobri ${ }^{1}$, Mohamad Taha $\mathrm{Ijab}^{2 *}$, Norshita Mat Nayan ${ }^{3}$, Alexander Edo Tondas ${ }^{4}$, Paisal $^{5}$ \\ 1 Faculty of Vocational, Universitas Bina Darma, Indonesia \\ Email: sobri@binadarma.ac.id \\ 2 Institute of IR4.0, Universiti Kebangsaan Malaysia, Malaysia \\ Email: taha@ukm.edu.my \\ 3 Institute of IR4.0, Universiti Kebangsaan Malaysia, Malaysia \\ Email: norshitaivi@ukm.edu.my \\ 4 Department of Cardiology \& Vascular Medicine, Dr. Mohammad Hoesin General Hospital, Indonesia \\ Email: tondas2000@gmail.com \\ $5 \quad$ Faculty of Computer Science, Universitas Sjakhyakirti, Indonesia \\ Email: paisal@unisti.ac.id \\ Corresponding Author
}

\section{Article Info:}

\section{Article history:}

Received date: 15.08 .2020

Revised date: 30.08 .2020

Accepted date: 10.09 .2020

Published date: 15.09 .2020

\section{To cite this document:}

Sobri, M., Ijab, M. T., Mat Nayan, N., Tondas, A. E., \& Paisal. (2020). Design of Mobile Heart Disease Application Based on Users' Perspective Using Design Science Research Method. Journal of Information System and Technology Management, 5 (18), 61-75.

DOI: $10.35631 /$ JISTM.518007.

\begin{abstract}
:
In the era of the Fourth Industrial Revolution (4IR), many mobile heart disease applications are available on Apple App Store and Google Play and these applications enable heart patients to carry out self-monitoring of their heart conditions practically easily. However, when the user feels dissatisfied with the usability and affordances of the mobile heart disease application, it impacts the user satisfaction level to the extent that the users do not use it anymore. The user satisfaction level is a very important factor in the usability of any mobile application including mobile heart disease application which is comfortable and pleasant for continuous use. This paper uses the User-Centered Design (UCD) method towards understanding users' perspective as the problem of lack of user satisfaction affects the usability and affordances of mobile heart disease applications. This study recruits twenty heart patients and four cardiologists in a hospital in Palembang, Indonesia for designing a mobile heart disease prototype called HeartM. The prototype has several features including measuring the patient's heart rate, recording heart rate, chatting, sending reminders, and configuring system settings. The focus of this paper is on the design of the mobile heart disease application on its usability, affordances, and user satisfaction aspects based on the user's perspective. The overall study adopts the Design Science Research (DSR) approach. DSR approach involves several iterations to ensure the final prototype produces a better design
\end{abstract}




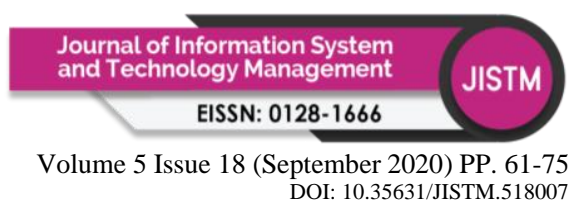

compared to its previous iterations. This paper contributes to design knowledge and offers recommendations particularly for the design of mobile heart disease applications.

Keywords:

Mobile Application, Heart Disease, Usability, Affordances, Satisfaction

\section{Introduction}

Heart disease is one of the chronic diseases causing the highest deaths in the world other than cancer, diabetes, and tuberculosis (Dariush et al., 2016). In Malaysia, heart disease was reported by the Department of Statistics Malaysia (2019) to be the highest compared to stroke, pneumonia, and chronic lower respiratory disease in 2018.

In the era of the 4IR (Fourth Industrial Revolution), heart disease patients are able to monitor their hearts' conditions using mobile heart disease applications which are available on major platforms such as Google Play for Android devices and Apple App Store for iOS devices, and they are available for free download while some applications are for purchase around USD 2.84 - USD 9.62 (Sobri, Ijab, and Nayan, 2018). User satisfaction is a very important aspect in usability to identify the affordances of mobile heart diseases application is comfortable, and pleasant for future use. When the user feels dissatisfied with the usability and affordances of the mobile heart disease application, it will directly impact user satisfaction level such that the user may not use it anymore.

Based on previous studies on user satisfaction, specifically on usability topics, researchers found that high level of affordances can influence the usability of mobile heart disease applications. Some research (Collen and Miller, 2015; Khajouei, De Jongh, and Jaspers, 2009; Menachemi and Collum, 2011; Yucel, Cebi, Hoege, and Ozok, 2012) argue that software designers of any mobile applications often do not think deeply about the needs of their users. Thus, User Centered Design (UCD) should be adopted in the design and development of such mobile applications. Additionally, Kamana (2016) and Sobri et al (2019) claim that many mobile heart disease applications do not have the features expected and needed by the patients. Further, mobile heart disease applications do not support interactive communication between heart patients with their cardiologists (Ribeiro, Moreira, Almeida, and Santos-Silva, 2017) and have poor usability (Kraleva, 2017).

Given these issues in the literature, designing an effective usability of mobile heart disease application is a big challenge. A good usability of mobile heart disease application should be simple, and easy so that it is more comfortable, pleasant, and efficient to work with. Based on research recommendations (Azevedo and Sousa, 2015; Majeed-Ariss et al., 2015; Zahra, Hussain, and Mohd, 2018), more research should study the involvement of end users i.e. heart patients and cardiologists in the design of mobile heart disease applications. Some of researchers the involvement of end users in their study: Nazlena et al (2012) made design of an interactive digital nutritional education package for elderly people, Hazwani et al (2016) designing a persuasive physical activity application for older workers, Mohamad Hidir et al (2017) built of mobile application healthy diet for elderly, and Irna et al (2018) built of game design for cancer patients. Therefore, this paper aims to design of mobile heart disease application by adopting the UCD in gathering design inputs from the users perspective. 
This paper begins with a review of literature on usability, and affordances. It continues with the research methods employed in this study. In the subsequent section, the results on the mobile heart disease application called HeartM are presented. The paper wraps with a brief conclusion and salient points for further research.

\section{Literature Review}

The collected relevant articles were analyzed using pertinent concepts related to usability, and affordances constructs.

\section{Usability}

ISO 9241-11 defines usability as the extent to which a product can be used by specified users to achieve specified goals with effectiveness, efficiency and satisfaction, in a specified context of use (ISO, 1994). Russ et al (2013) define usability as measurement of the quality of a user's experience when interacting with a product or system. The summary and comparison of the various usability elements discussed by previous researchers such as Nielsen (1993), ISO (1994), Shneiderman (2000), Rachel et al (2013), and Fatima et al (2018) are shown in Table 1 .

Table 1. Comparison of Usability Elements Studied by Previous Researchers

\begin{tabular}{|c|c|c|c|c|c|}
\hline \multirow[t]{2}{*}{ Usability Elements } & \multicolumn{5}{|c|}{ Researchers } \\
\hline & $\begin{array}{c}\text { Nielsen } \\
(\mathbf{1 9 9 3 )}\end{array}$ & $\begin{array}{c}\text { ISO } \\
(1994)\end{array}$ & $\begin{array}{c}\text { Shneiderman } \\
(2000)\end{array}$ & $\begin{array}{l}\text { Rachel et } \\
\text { al (2013) }\end{array}$ & $\begin{array}{c}\text { Fatima } \\
\text { et al } \\
(2018)\end{array}$ \\
\hline Learnability & $\checkmark$ & & & $\checkmark$ & $\checkmark$ \\
\hline Effectiveness & $\checkmark$ & $\checkmark$ & & $\checkmark$ & $\checkmark$ \\
\hline Memorability & $\checkmark$ & & & & \\
\hline Error & $\checkmark$ & & $\checkmark$ & $\checkmark$ & \\
\hline Satisfaction & $\checkmark$ & $\checkmark$ & $\checkmark$ & $\checkmark$ & $\checkmark$ \\
\hline Efficiency & & $\checkmark$ & & $\checkmark$ & $\checkmark$ \\
\hline Time to Learn & & & $\checkmark$ & & \\
\hline Speed of performance & & & $\checkmark$ & & \\
\hline Retention Over Time & & & $\checkmark$ & & \\
\hline Awareness & & & & $\checkmark$ & \\
\hline Cognitive Load & & & & $\checkmark$ & \\
\hline Information Security & & & & & $\checkmark$ \\
\hline Function & & & & & $\checkmark$ \\
\hline
\end{tabular}

Based on Table.1, previous studies have similarities i.e. having a usability element of satisfaction in their discussion of usability. This shows that satisfaction is one of the most important elements of usability in the use of a system or application developed. In addition, Kamana (2016) claim that when satisfaction is considered with the needs of patients, the patients will then be completely satisfied from the mobile heart disease applications developed for their use. Therefore, this study focuses on the element of usability that is satisfaction only. 


\section{Affordances}

This theory was first proposed by Gibson (1978) who studies what and how users interact with objects that influence user satisfaction. The concept of affordances is then adopted by many researchers in the field of Human Computer Interaction (HCI). Namely, Norman (1988) associates the ability of a system (i.e., its affordances) with the usability of an object, especially the basic properties that determine how it can be used. He argues that the technology is designed with the affordances to interact clearly for the user to use for example: (i) the door is designed so that it is clear whether it should be pulled or pushed to open, (ii) press the button first before using the elevator, (iii) the use of smartphones that have a lot of interaction, when the user interacts with touch, press, swipe, drag, and other gesture must be clearly planned and designed such that those gestures would afford the specific task(s) to be executed and this would have an impact on user satisfaction.

Recently, according to Anderson (2011) affordances has become a policy theory for HCI. Kirschner et al (2004) use affordances in their study of computer supported collaborative learning (CSCL) use among educators, students and researchers. They develop a framework that explained the usefulness of an electronic-based learning environment is determined by several forms of affordances namely: educational affordances, social affordances, and technological affordances. Tang and Hew (2018) advance the previous study of Kirschner et al (2004) and use the educational affordances concept to explain mobile instant messaging (MIM) use to support teaching and learning activities either in or out of the classroom. Further, Kirschner et al (2004) state that social affordances refer to the characteristics of tools that enable social interaction between participants, with the aim of enhancing group cohesion and a sense of belonging. Lastly, technological affordances show the design features of tools that allow users to complete specific tasks that can satisfy users (Kirschner et al 2004).

A study using affordances theory in health field (medical) was conducted by Strong et al (2009) whereby they developed a model that adapts the affordances theory to realize the use of electronic health record (EHR) in clinics. They suggest the concept of actualization, or active involvement of users with the affordances to produce specific goals.

The proposed affordance in this particular paper are as follows: (i) Medical affordances as the context of this study is for heart diseases that provides the affordances of heart patients to check their own heart diseases in addition to the prototype that will be developed has the affordances to remind heart patients to take medication on time. (ii) Social affordances, the social affordances in this study is to allow the heart patient to send his or her recording results to a cardiologist, and to allow for talking about his or her illness between the heart patient and the cardiologist. Lastly, (iii) technological affordances, the technological affordances used in this study are by leveraging the technological affordances of existing smartphone features such as cameras and flashlights called photoplethysmography (PPG) which uses the user's finger tissue for heart rate measurement (White and Flaker, 2017).

\section{Research Methods}

The design and evaluation process of mobile heart disease prototype called HeartM was performed for 4 (four) months (10th February until 10th June 2020) and adopts the User Centered Design (UCD) method based on Collen and Miller (2015). The problem of lack of user satisfaction affects the usability and affordances of mobile heart diseases application. As 


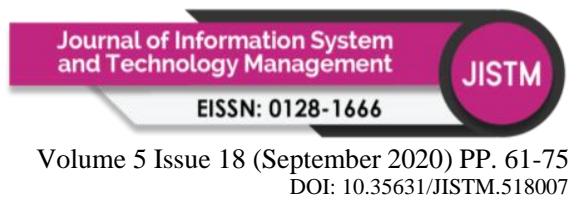

per the UCD method, the target users for this current study are the heart patients and cardiologists. The heart patients and cardiologists can give an opinion and evaluation of the design prototype HeartM with the use of survey questionnaires and interviews (Schnall et al., 2016).

There are four (4) cardiologists at Dr. Mohammad Hoesin Hospital Palembang randomly selected to assist in this study. They have more than ten (10) years' experience each and are highly qualified cardiologists. Prior to their involvement, the cardiologists signed an informed consent letter to voluntarily lend their assistance in the study. Additional, twenty (20) heart patients at Myria Hospital Palembang also participated in the study. The heart patients have agreed to participate in the research by signing informed consent letter. Demographically, there are 3 male cardiologists and 1 female cardiologists while there were $65 \%$ male and $35 \%$ female heart patients. For data analysis, a qualitative analysis was conducted with the aim of identifying user satisfaction of design of HeartM. Figure 1 shows some of the participants involved in this study.
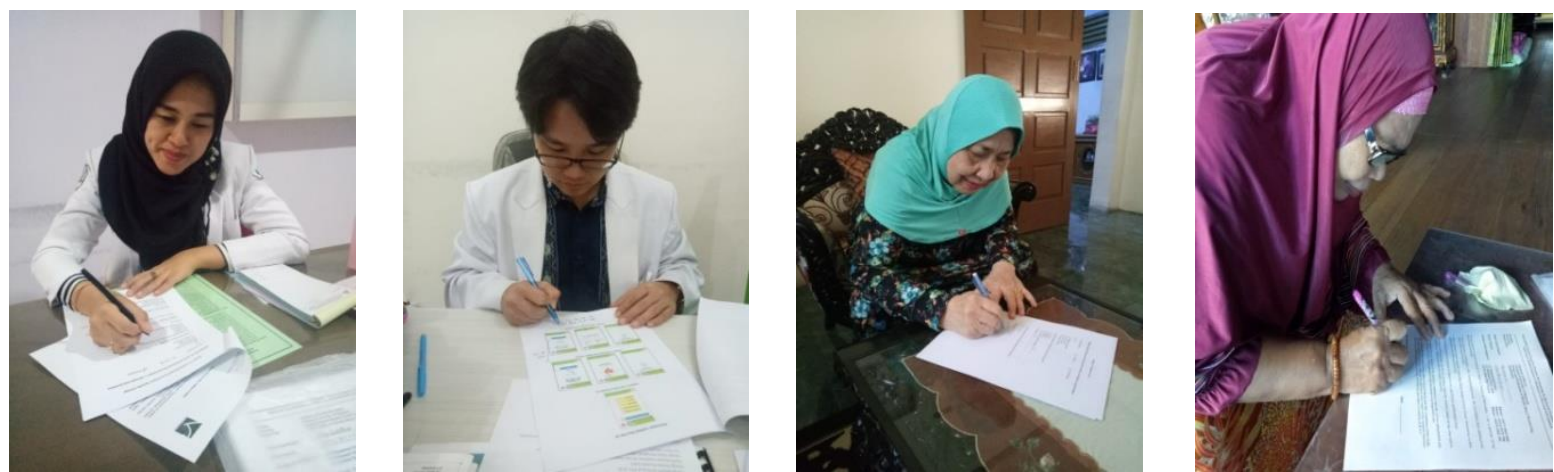

Figure 1. Some of The Participants in This Study (Photos Used with Permission)

For the design and evaluation of HeartM, this study proposes three iterations of HeartM. This section also presents the methods in conducting to design of HeartM using the Design Science Research (DSR) approach. Hevner (2007) defines DSR as a design science that is more focused on the creation of new and innovative 'artifacts' to solve problems. Hevner et al. (2004) define 'artifacts' as forms, models, methods or instantiations (prototypes or systems developed).

DSR approach consits of environment, rigor and the knowledge base. Environment is a "problem space" that consists of people, organizational systems and technical systems that are interconnected with each other, working towards the same goal. Hevner (2007) suggests that good design science (DSR) research should begin by identifying problems or opportunities in the environment. The rigor cycle "bridges" the surrounding environment with DSR which provides the need to serve as input for research activities. In this research, the environment refers to users, namely heart patients and cardiologists and identifies real heart disease problems that were previously only known to researchers through literature review Study 1 (Sobri et al., 2018) and usability evaluation from existing mobile heart disease applications that have been done in Study 2 (Sobri et al., 2019).

Meanwhile, the knowledge base consists of existing theoretical foundations, scientific methods, models, products, processes produced from previous information systems research. 
The meticulous cycle connects the knowledge base with DSR which provides past knowledge as reference material into DSR activities. For example, the knowledge base in this study consists of heart disease, usability of heart disease health mobile applications, and user interface design concepts, data collection methods (i.e., interviews with heart patients and cardiologists, PSSUQ questionnaires and observations) and data analysis methods (descriptive). The precision cycle provides constructs based on affordances theory as the material referred to in the DSR activities of this research.

The main component of DSR is the design cycle which involves the process of repetition and evaluating artifacts (i.e., the iterations in the design process). This cycle involves the production of several alternatives and design evaluation of a given need. As mentioned earlier, in DSR, requirements are inputs from the relevance cycle, while the theories and methods used to construct and evaluate these design alternatives are inputs from the rigor cycle. According to Hevner (2007) this shows the dependence of the design cycle with the two cycles in the mandatory research activities in the DSR project. Artifacts generated from the DSR process are then evaluated in the environment, which will determine whether additional iteration of the relevance cycle is required. If all the requirements have been met and satisfied, then the rigor cycle adds these newly produced artifacts to the knowledge base for reference in future research and practice. Figure 2 shows adoption of DSR approach in this study to design of HeartM. 


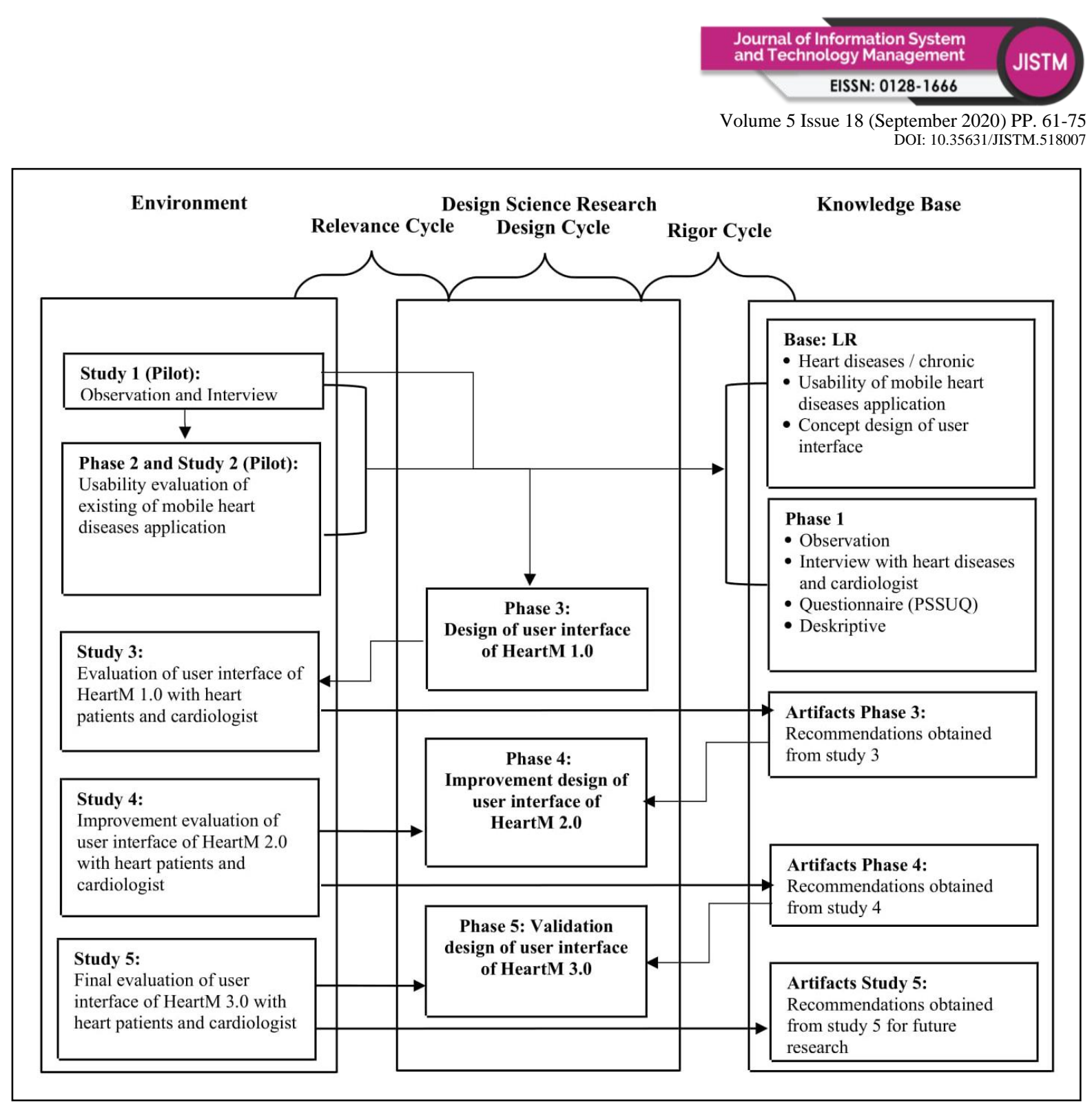

Figure 2. Design and Evaluation Process of HeartM

\section{Results}

This section presents the results of each design and evaluation process of HeartM described in the previous section. The first study of design is to identify requirements. In this study, the main researcher met the participants (heart patients and cardiologists) who have agreed to participate in the study to seek their insights on the propose features of HeartM. The questions asked to the participants are shown in Table 2.

Table 2. The Interview Questions to Identify Requirements to Propose Design of HeartM

\begin{tabular}{cll}
\hline No & \multicolumn{1}{c}{ Questions } & \multicolumn{1}{c}{ Summary Answers from Participants } \\
\hline 1 & $\begin{array}{l}\text { To monitor heart disease what needs } \\
\text { to be checked }\end{array}$ & Heart rate, blood pressure, record, and chat \\
\hline 2 & Information available in HeartM & Record of heart rate \\
\hline 3 & $\begin{array}{l}\text { The color used for the application } \\
\text { consists of several colors or only 1 } \\
\text { color }\end{array}$ & Various bright colors \\
\hline
\end{tabular}




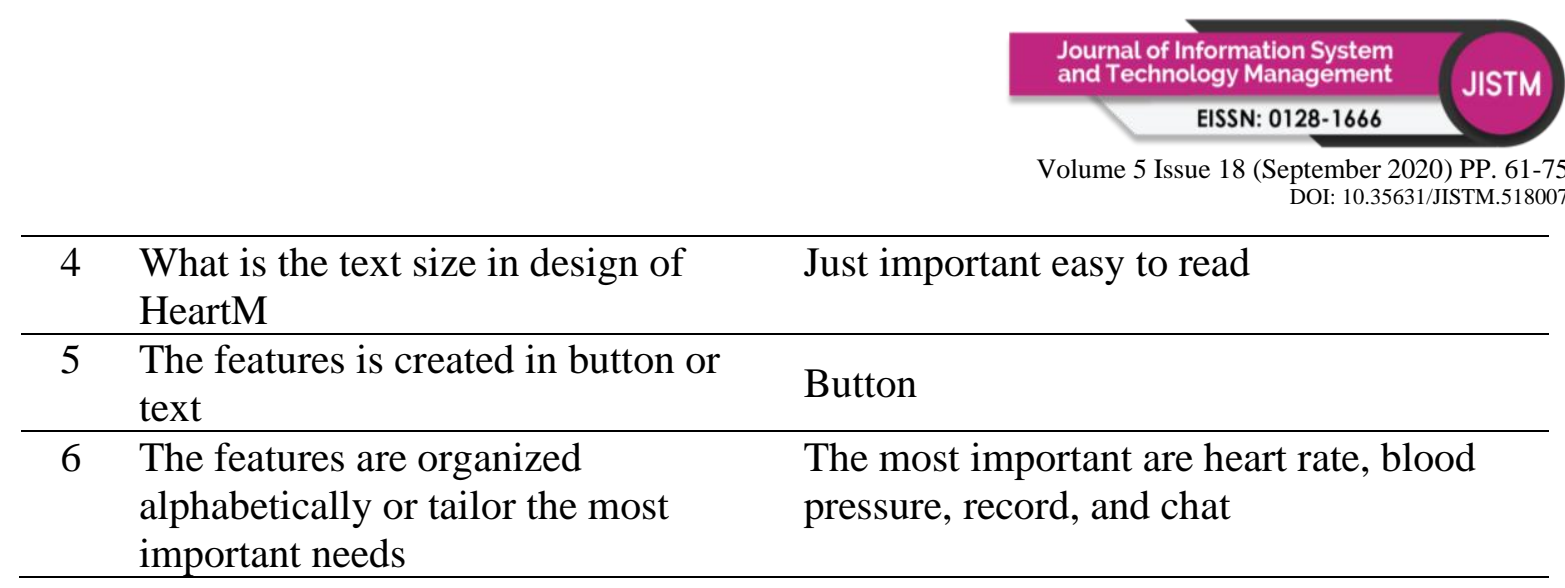

After doing the first study, the second study was to identify usability issues of existing mobile heart disease application available on platforms Google Play and Apple App Store. The second study found that the applications: (i) offer peripheral features unnecessary to the users, (ii) slowness in providing results (i.e., measurement and/or feedback), (iii) unmemorable features, and (iv) results of measurements are perceived to be dubious and unreliable (Sobri et al., 2019). The findings of the first study and the second study were used to design HeartM 1.0 (the first iteration). Figure 3 shows the main interface of HeartM 1.0 (the first iteration) which has several features including measuring heart patient's heart rate and blood pressure rate, treatment record, forum, and chat.

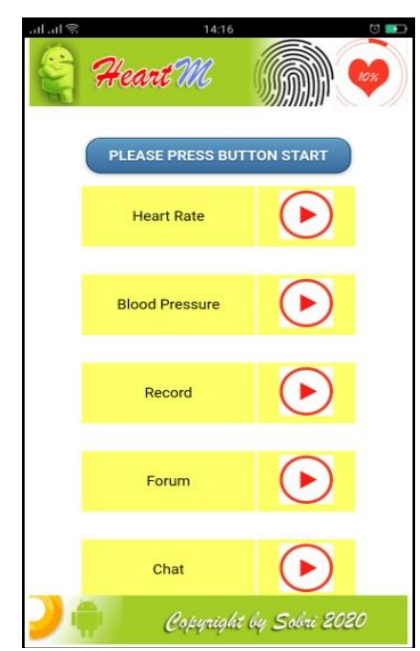

Figure 3. Main Interface of HeartM 1.0

For the evaluation of HeartM 1.0, this first iteration used the high-fidelity of HeartM 1.0. According to Chávez et al (2019) defined high-fidelity as a realistic representation of the application (i.e. HeartM 1.0). In Study 3, the main researcher met the participants (heart patients and cardiologists) who have agreed to participate in the study to seek their insights on the features of HeartM 1.0. After that, the participants give opinion based on their evaluations of the high-fidelity HeartM 1.0. Figure 4 shows examples of the proposed improvements suggested by the participants to HeartM 1.0 


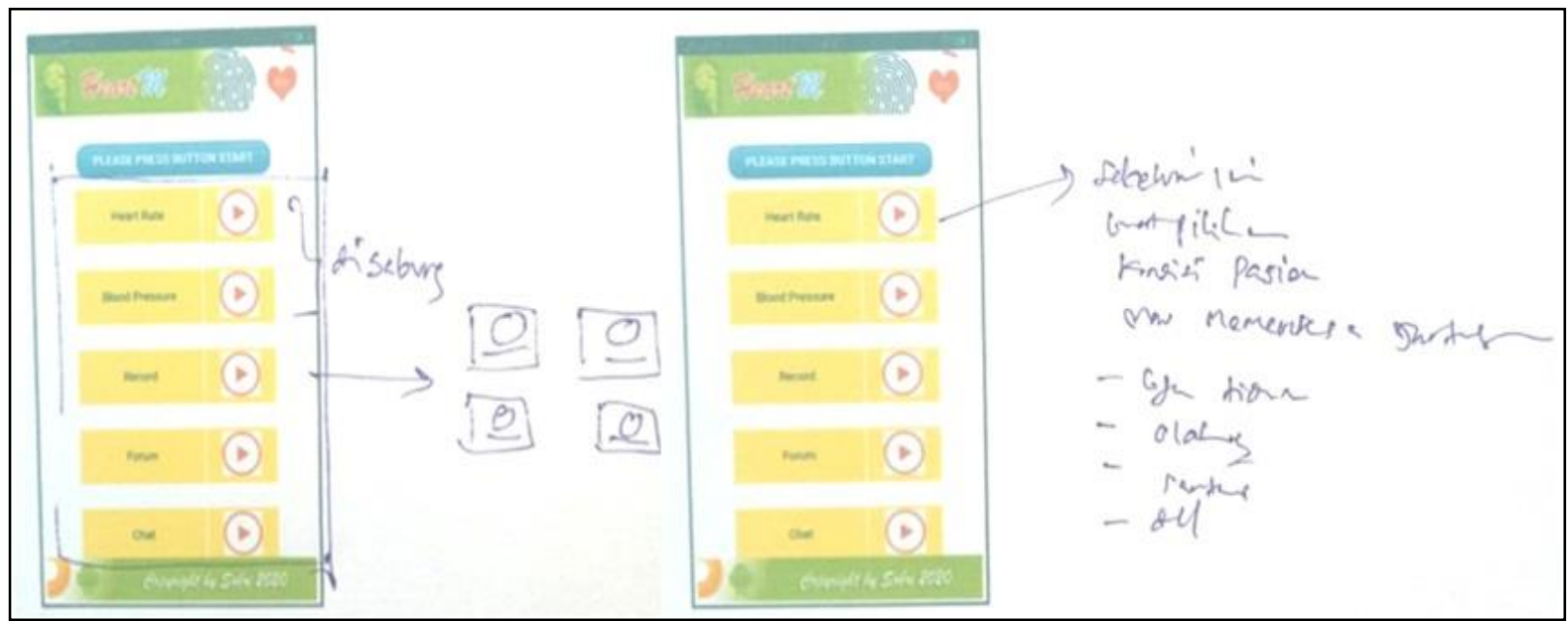

Figure 4. Examples of The Proposed Improvements Suggested by The Participants

The finding of Study 3 used to improve the high-fidelity version of HeartM 1.0 to include the affordances aspects into the HeartM 2.0 (i.e., the second iteration). Figure 5 shows the main interface of HeartM 2.0 prototype which has 5 (five) features: (i) measurement heart rate, (ii) record heart rate, (iii) chat, (iv) reminder, and (v) setting.

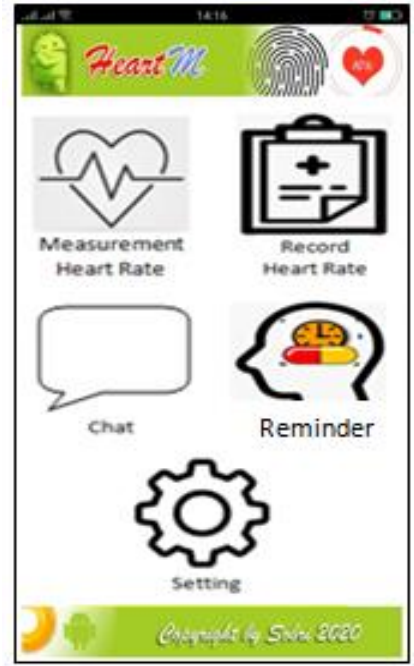

Figure 5. Main Interface of Mock-up Prototype HeartM 2.0

The detail of mock-up prototype HeartM 2.0 in this study are as follows:

\section{Medical Affordances}

Medical affordances in the context of this study is the medical aspects for heart diseases that provides the affordances of heart patients to check their own heart diseases in addition to the prototype that will be developed has the affordances to remind heart patients to take medication on time. After the heart patient clicks this icon, $\stackrel{y}{=}$ the application will present the interfaces as shown in Figure 6. 


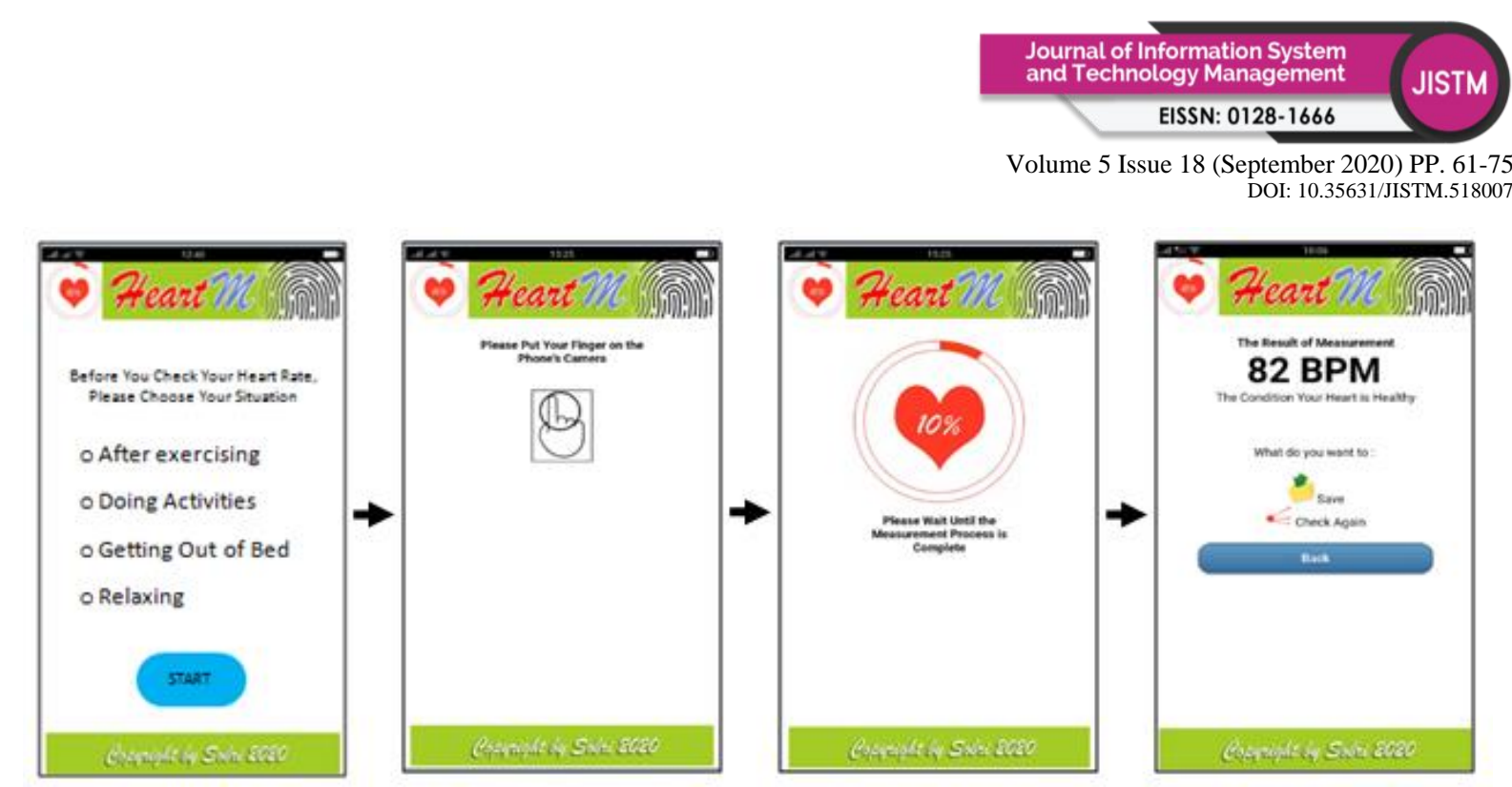

Figure 6. The Flow of Process to Measurement Heart Rate (The Medical Affordances of HeartM 2.0)

\section{Social Affordances}

Social affordances in the context of this study is to allow the heart patient to communicate about his or her illness with other heart patients as well as with their Cardiologist. After heart patient or cardiologist click $\square$, this icon, interfaces shown in Figure 7 are presented as to make it easy for the heart patients to chat with their Cardiologist. Further HeartM 2.0 has guide of themes to support chat functions shown in Table 3.

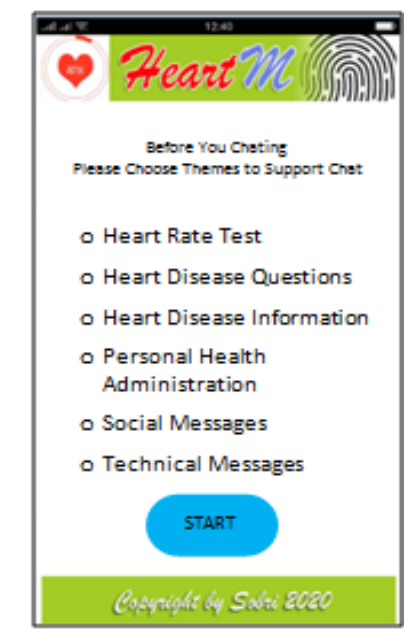

Figure 7. Feature of Chat in HeartM 2.0 


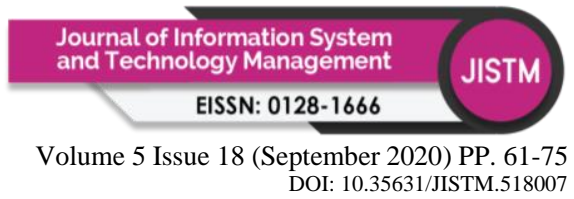

Table 3. The Proposed of Variant of Themes to Support Chat Functions of HeartM 2.0

Theme

Heart rate tests

Heart disease questions

Heart disease information

Personal health

administration

Social messages

Technical messages

\section{EXAMPLE}

Today, my heart rate reading was at $70 \mathrm{BPM}$

What needs to be checked to monitor my heart conditions?

Many available mobile heart application in Play Store, and

Apple App Store for purchase, and free

Can I cancel the check up and change to tomorrow, please ?

Please, keep your cholesterol level low.

Dear all my patients, I'm sorry, tomorrow I will not be at the hospital, thanks a lot.

\section{Technological Affordances}

Lastly, the technological affordances used in this study are by leveraging the technological capabilities of existing smartphone features such as cameras and flashlights called photoplethysmography (PPG) shown in Figure 6.

To evaluate of mock-up prototype HeartM 2.0, the main researcher met and installed in the participants' smartphones (Android devices). Examples of some of the participants who evaluated HeartM 2.0 shown in Figure 8.
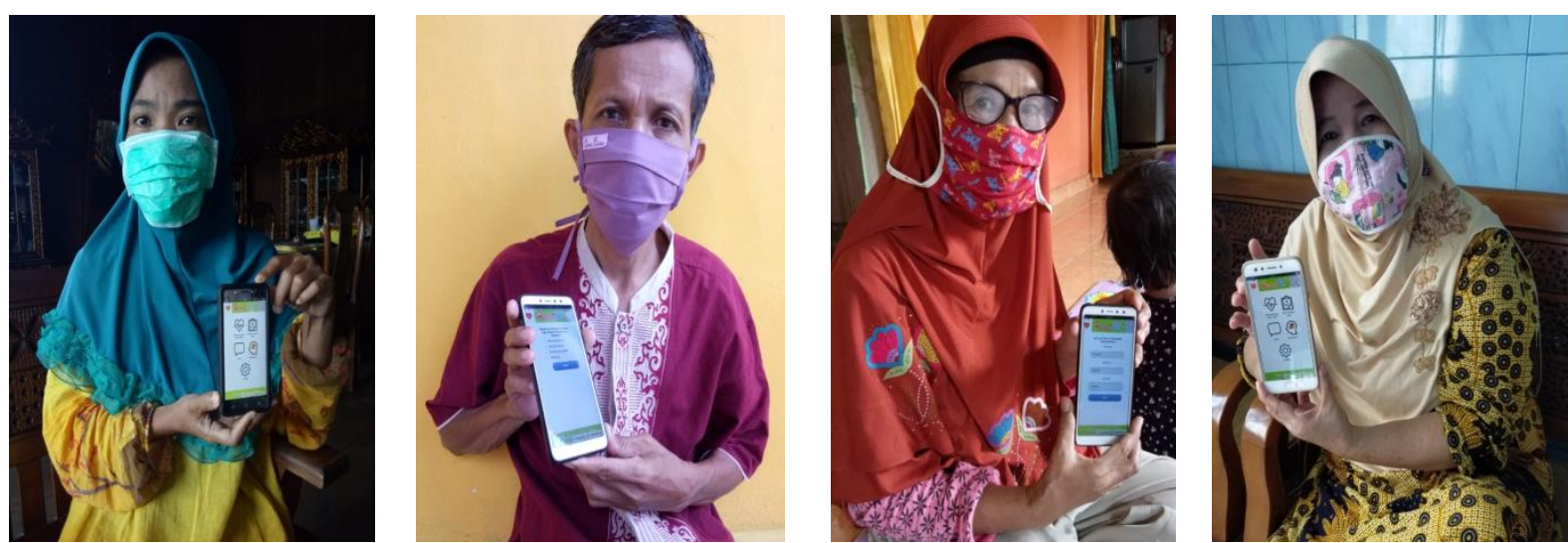

Figure 8. Some of The Participants Who Evaluated HeartM 2.0

In Study 4, the participant evaluated HeartM 2.0 by filling in the questionnaires, and use Likert scale of possible responses ranges from 1 (very unsatisfied), 2 (unsatisfied), 3 (neither), 4 (satisfied), and 5 (very satisfied). The questionnaires adapted standard questionnaires (Assila, De Oliveira, and Ezzedine, 2016). The following are the results of statistical calculations based on indicators in term of usability, affordances, and satisfaction. For descriptive statistics on the evaluation of the mock-up prototype of HeartM 2.0, it was calculated from the perspective of each participant. Table 4 presents the comparison from perspectives of participants $(\mathrm{C}$ for cardiologist and HP for heart patients) who evaluated the mock-up prototype of HeartM 2.0 for each types of affordances ( $\mathrm{M}$ for medical, $\mathrm{S}$ for social, and $\mathrm{T}$ for Technological). 
Table 4. Comparison Perspective from The Each Participant

\begin{tabular}{|c|c|c|c|c|c|}
\hline \multirow[t]{2}{*}{ Participants } & \multicolumn{5}{|c|}{ Usability Criteria to Satisfaction of Affordances of HeartM 2.0} \\
\hline & $\begin{array}{c}\text { I'm } \\
\text { satisfied } \\
\text { with the } \\
\text { features } \\
\text { provided } \\
\text { of HeartM } \\
\mathbf{2 . 0}\end{array}$ & $\begin{array}{l}\text { I'm satisfied } \\
\text { with design of } \\
\text { the features } \\
\text { provided of } \\
\text { HeartM } 2.0\end{array}$ & $\begin{array}{c}\text { I'm satisfied } \\
\text { with image } \\
\text { used of } \\
\text { HeartM } 2.0\end{array}$ & $\begin{array}{c}\text { I'm } \\
\text { satisfied } \\
\text { with } \\
\text { functions } \\
\text { of HeartM } \\
\mathbf{2 . 0}\end{array}$ & $\begin{array}{l}\text { Overall, I } \\
\text { am } \\
\text { satisfied } \\
\text { with } \\
\text { HeartM } \\
2.0\end{array}$ \\
\hline
\end{tabular}

\begin{tabular}{|c|c|c|c|c|c|c|c|c|c|c|c|}
\hline & & $\mathbf{M}$ & $\mathbf{S}$ & $\mathbf{T}$ & $\mathbf{M}$ & $\mathbf{S}$ & $\mathbf{T}$ & $\mathbf{M}$ & $\mathbf{S}$ & $\mathbf{T}$ & \\
\hline $\mathrm{C} 1$ & 3 & 3 & 3 & 3 & 4 & 4 & 3 & 4 & 4 & 3 & 3 \\
\hline $\mathrm{C} 2$ & 3 & 4 & 3 & 3 & 4 & 3 & 3 & 4 & 3 & 3 & 3 \\
\hline $\mathrm{C} 3$ & 3 & 4 & 4 & 3 & 3 & 3 & 3 & 3 & 3 & 3 & 3 \\
\hline $\mathrm{C} 4$ & 3 & 3 & 3 & 3 & 3 & 3 & 3 & 3 & 3 & 3 & 3 \\
\hline HP1 & 4 & 4 & 4 & 4 & 4 & 4 & 4 & 4 & 4 & 4 & 4 \\
\hline HP2 & 4 & 4 & 3 & 4 & 4 & 3 & 4 & 4 & 3 & 4 & 4 \\
\hline HP3 & 3 & 3 & 3 & 3 & 3 & 3 & 3 & 3 & 3 & 3 & 3 \\
\hline HP4 & 3 & 3 & 3 & 4 & 3 & 4 & 3 & 4 & 3 & 3 & 3 \\
\hline HP5 & 4 & 4 & 4 & 3 & 4 & 4 & 3 & 4 & 4 & 3 & 4 \\
\hline HP6 & 3 & 3 & 4 & 3 & 3 & 3 & 4 & 3 & 3 & 4 & 3 \\
\hline HP7 & 3 & 4 & 3 & 3 & 3 & 4 & 3 & 3 & 4 & 3 & 3 \\
\hline HP8 & 4 & 3 & 4 & 4 & 4 & 3 & 4 & 4 & 3 & 4 & 4 \\
\hline HP9 & 4 & 4 & 4 & 3 & 3 & 4 & 4 & 3 & 4 & 4 & 4 \\
\hline HP10 & 3 & 4 & 3 & 3 & 3 & 3 & 4 & 3 & 4 & 3 & 3 \\
\hline HP11 & 4 & 4 & 4 & 4 & 4 & 4 & 4 & 4 & 4 & 4 & 4 \\
\hline HP12 & 4 & 4 & 4 & 3 & 4 & 4 & 3 & 4 & 4 & 3 & 4 \\
\hline HP13 & 3 & 3 & 4 & 3 & 3 & 4 & 3 & 4 & 3 & 3 & 3 \\
\hline HP14 & 4 & 4 & 3 & 4 & 3 & 3 & 4 & 3 & 4 & 4 & 4 \\
\hline HP15 & 3 & 3 & 3 & 4 & 3 & 4 & 3 & 4 & 3 & 3 & 3 \\
\hline HP16 & 4 & 4 & 4 & 3 & 4 & 4 & 3 & 4 & 3 & 4 & 4 \\
\hline HP17 & 3 & 4 & 3 & 3 & 4 & 3 & 3 & 4 & 3 & 3 & 3 \\
\hline HP18 & 3 & 4 & 3 & 3 & 3 & 3 & 4 & 3 & 3 & 4 & 3 \\
\hline HP19 & 4 & 3 & 4 & 4 & 4 & 3 & 4 & 4 & 4 & 3 & 4 \\
\hline HP20 & 4 & 4 & 4 & 3 & 4 & 3 & 4 & 3 & 3 & 4 & 4 \\
\hline
\end{tabular}

Based on Table 4, the findings of the evaluation of mock-up prototype of HeartM 2.0 from the perspective of each participants are: in terms of features have average score of 3.45 because according to them, it has the fewest number of main (necessary) features so easy to remember. Meanwhile, in term of design of the features affordances to medical affordances the average score was 3.62, to social affordances the average score was 3.5 and technological affordances the average score was 3.33 .

Whereas, in term of image used of HeartM 2.0, the average score was 3.5 to medical affordances, to social affordances the average score was 3.45, and to technological affordances the average score 3.45 . For in term of functions the average score was 3.58 to medical 


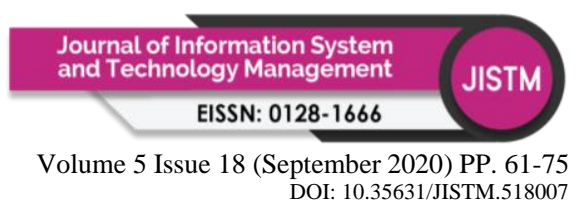

affordances, to social affordances the average score was 3.41, and to technological affordances the average score 3.41. It can be deduced that the cardiologists are not yet satisfied with the mock - up prototype of HeartM 2.0.

\section{Conclusion}

The design process and evaluations of the mobile heart disease application called HeartM discovered that user perspective is crucial to ensure users' satisfaction as well as in ensuring overall usability and affordances of the HeartM. This paper contributes in recommending to designers to produce better design for chronic diseases in general and for the mobile heart diseases application in particular. Further research will focus on improving and on the final iteration (the third iteration) evaluation to for HeartM 3.0, also based on the users' perspective.

\section{Acknowledgment}

This study is supported by Universiti Kebangsaan Malaysia under grant Geran Penyelidikan Khas Top Down UKM (GPK-4IR-2020-017).

\section{References}

Anderson, C. (2011). Health information systems affordances: How the materiality of information technology enables and constrains the work practices of clinicians. ProQuest Dissertations Publishing, 141. Retrieved from https://search.proquest.com/docview/916613745?pq-origsite=summon

Assila, A., De Oliveira, K., \& Ezzedine, H. (2016). Standardized Usability Questionnaires: Features and Quality Focus. Journal of Computer Science and Information Technology (EJCSIT), 6(1), 15-31.

Azevedo, R., \& Sousa, H. (2015). Future perspectives of Smartphone applications for rheumatic diseases self- management, (March). doi:10.1007/s00296-014-3117-9

Chávez, A., Borrego, G., Gutierrez-Garcia, J. O., \& Rodríguez, L. F. (2019). Design and evaluation of a mobile application for monitoring patients with Alzheimer's disease: A day center case study. International Journal of Medical Informatics, 131(August), 103972. doi:10.1016/j.ijmedinf.2019.103972

Chief Statistician Malaysia. (2019). Statistics on Causes of Death in Malaysia. Departement of Statistics Malaysia (Vol. 188). Kuala Lumpur. https://doi.org/10.1017/CBO9781107415324.004

Collen, M. F., \& Miller, R. A. (2015). The History of Medical Informatics in the United States (pp. 339-383). London: Springer. Retrieved from https://books.google.co.id/books?id=Vf2zCgAAQBAJ\&pg=PA339\&lpg=PA339\&dq $=$ The+History + of + Medical+Informatics + in + the + United + States, + in:+M.F.+Collen, + R .A.+Miller+(Eds. $),+$ The + Early+History+of+Hospital+Information+Systems + for + Inpa tient+Care+in+the+United+States \&

Dariush, M., Benjamin, E. J., Go, A. S., Arnett, D. K., Blaha, M. J., Cushman, M., ... Turner, M. B. (2016). Heart Disease and Stroke Statistics-2016 Update. Circulation (Vol. 133). American Heart Association. doi:10.1161/CIR.0000000000000350

Fatima, Z., Haslina, M., Azham, H., \& Mazni, O. (2018). Usability Dimensions for Chronic Disease Mobile Applications: A Systematics Literature Review. In Knowledge Management International Conference (KMICe) (pp. 363-368). Miri Sarawak: Universiti Utara Malaysia. Retrieved http://www.kmice.cms.net.my/ProcKMICe/KMICe2018/pdf/CR97.pdf 


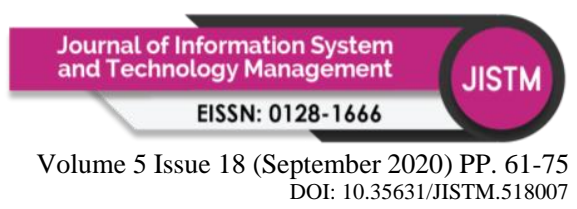

Gibson, J. J. (1978). The Ecological Approach to the Visual Perception of Pictures. Leonardo, pp. 227-235. doi:10.2307/1574154

Hazwani, M. M., Nazlena, M. A., \& Alan, F. S. (2016). Designing a persuasive physical activity application for older workers: understanding end-user perceptions. Behaviour \& Information Technology, 35(12), 1102-1114. doi:10.1080/0144929X.2016.1211737

Hevner, A. R. (2007). A Three Cycle View of Design Science Research. Scandinavian Journal of Information Systems, 19(2), 1-6. Retrieved from http://aisel.aisnet.org/sjis\%0Ahttp://aisel.aisnet.org/sjis/vol19/iss2/4

Irna, H., A. Imran, N., Hamidah, A., Nadhirah, R., \& Hanif, B. (2018). Game Design Requirements Through Ethnography Amongst Pediatric Cancer Patients. Advanced Science Letters, 24(3), 1567-1570. doi:10.1166/asl.2018.11110

ISO. (1994). Ergonomic requirements for offi ce work with visual display terminals. Part 11: Guidance on usability (ISO DIS 9241-11) (ISO DIS 92). London: International Standards Organization.

Kamana, M. (2016). Investigating usability issues of mHealth apps for elderly people. Blekinge Institute of Technology.

Khajouei, R., De Jongh, D., \& Jaspers, M. W. M. (2009). Usability evaluation of a computerized physician order entry for medication ordering. Studies in Health Technology and Informatics, 150, 532-536. doi:10.3233/978-1-60750-044-5-532

Kirschner, P., Strijbos, J. W., Kreijns, K., \& Beers, P. J. (2004). Designing electronic collaborative learning environments. Educational Technology Research and Development, 52(3), 47-66. doi:10.1007/BF02504675

Majeed-Ariss, R., Baildam, E., Campbell, M., Chieng, A., Fallon, D., Hall, A., ... Swallow, V. (2015). Apps and adolescents: A systematic review of adolescents' use of mobile phone and tablet apps that support personal management of their chronic or long-term physical conditions. Journal of Medical Internet Research, 17(12), 1-16. doi:10.2196/jmir.5043

Menachemi, N., \& Collum, T. H. (2011). Benefits and drawbacks of electronic health record systems. Risk Management and Healthcare Policy, 4, 47-55. doi:10.2147/RMHP.S12985

Mohamad Hidir, M. S., Nazlena, M. A., \& Shahrul Azman, M. N. (2017). Mobile application on healthy diet for elderly based on persuasive design. International Journal on Advanced Science, Engineering and Information Technology, 7(1), 222-227. doi:10.18517/ijaseit.7.1.1725

Nazlena, A. M., Suzana, S., You Lee, K., Azir Rezha, N., \& Shahrul Azman, M. N. (2012). Design of an interactive digital nutritional education package for elderly people. Informatics for Health and Social Care, 37(4), 217-229. doi:10.3109/17538157.2012.654843

Nielsen, J. (1993). Usability Engineering. San Francisco: Morgan Kaufman.

Norman, D. (1988). The DESIGN of EVERYDAY THINGS (REVISED AN). New York: Basic Book. doi:10.1002/hfm.20127

Rachel, H., Derek, F., \& David, D. (2013). Usability of mobile applications: literature review and rationale for a new usability model. Journal of Interaction Science, 1(1), 1. doi:10.1186/2194-0827-1-1

Ribeiro, N., Moreira, L., Almeida, A. M. P., \& Santos-Silva, F. (2017). Pilot study of a smartphone-based intervention to promote cancer prevention behaviours. International 
doi:10.1016/j.ijmedinf.2017.10.013

Informatics, 108(February),

$125-133$.

Russ, A. L., Fairbanks, R. J., Karsh, B.-T., Militello, L. G., Saleem, J. J., \& Wears, R. L. (2013). The science of human factors: separating fact from fiction. BMJ Quality \& Safety, 22(10), 802-808. doi:10.1136/bmjqs-2012-001450

Schnall, R., Rojas, M., Bakken, S., Brown, W., Carballo-Dieguez, A., Carry, M., ... Travers, J. (2016). A user-centered model for designing consumer mobile health (mHealth) applications (apps). Journal of Biomedical Informatics, 60, 243-251. doi:10.1016/j.jbi.2016.02.002

Shneiderman, B. (2000). Universal usability. Communications of the ACM, 43(5), 84-91. doi:10.1145/332822.332843

Sobri, M., Ijab, M. T., \& Mat Nayan, N. (2019). Usability Evaluation of Heart Disease Monitoring Mobile Applications: A Comparative Study. In Advances in Visual Informatics (pp. 653-662). Springer, Cham.

Sobri, M., Ijab, M. T., \& Nayan, N. M. (2018). Systematic Literature Review untuk Membuat Model Aplikasi Pemantauan Kesehatan Cardiovascular. Jurnal Rekayasa Sistem Dan Teknologi Informasi, 2(2), 458-464.

Strong, D., Volkoff, O., Johnson, S., Pelletier, L., Bar-On, I., Tulu, B., ... Garber, L. (2009). A Theory of Clinic-EHR Affordance Actualization. In Proceedings of JAIS Theory Development Workshop. Sprouts: Working Papers on Information Systems (pp. 9-47).

Tang, Y., \& Hew, K. F. (2018). Examining the utility and usability of mobile instant messaging in a graduate-level course: A usefulness theoretical perspective. Australasian Journal of Educational Technology, 35(4), 128-143. doi:10.14742/ajet.4571

White, R. D., \& Flaker, G. (2017). Smartphone-based arrhythmia detection: Should we encourage patients to use the ECG in their pocket? Journal of Atrial Fibrillation, 9(6), 1-4. doi:10.4022/jafib. 1605

Yucel, G., Cebi, S., Hoege, B., \& Ozok, A. F. (2012). A fuzzy risk assessment model for hospital information system implementation. Expert Systems with Applications, 39(1), 1211-1218. doi:10.1016/j.eswa.2011.07.129

Zahra, F., Hussain, A., \& Mohd, H. (2018). Factors Affecting Mobile Health Application for Chronic Diseases. Journal of Telecommunication, Electronic and Computer Engineering, 10(1), 77-81. 